\title{
Analysing Pine Forest Ecosystems from Transylvania in the Context of Future Climatic Changes
}

\author{
Vlad Crișan ${ }^{1}(\mathbb{D})$, Lucian Dincă ${ }^{1 *}(\mathbb{D})$, Iuliana Gabriela Breabăn² ${ }^{\circledR}$ and Sorin Deca ${ }^{3}$ \\ 1 Marin Drăcea" National Institute for Research and Development in Forestry, 13 Closca Street, \\ 500040 Brasov, Romania, e-mail: vlad_crsn@yahoo.com; \\ 2 Alexandru Ioan Cuza" University of Iasi, 11 Bulevardul Carol I, 700506, Iaşi, România e-mail: \\ iulianab2001@gmail.com; \\ 3 3phD student at the Romanian Academy of Advanced Studies, 125 Calea Victoriei street, \\ Sector 1, 010071, Bucharest, Romania, e-mail: sorinstefan.deca@gmail.com; \\ * Correspondence: dinka.lucian@gmail.com;
}

Keywords: climate change, forest ecosystems, pine, Transylvania.

\begin{abstract}
A climatic modelling program was used in order to see the extent of changes in future climatic conditions. This can realize prognosis for certain climatic factors that cause extreme climatic phenomena concerning forest ecosystems. The program was applied for forest ecosystems comprised of Scots pine, installed and inventoried on sample surfaces from Transylvania. Simulations were then created within two future climatic scenarios. Two scenarios were chosen: the climatic scenario in which the increase of greenhouse gases would be moderate (rcp-4.5) and the climatic scenario in which the increase would be accentuated (rcp-8.5). The data was then processed, resulting in an analysis focused on the results of future climatic changes on forest ecosystems located in the studied area.

By analyzing all three pine stands, we can conclude that the Lechinta stand is the most vulnerable one if the two climatic parameters change.

It is necessary to verify and use future climatic scenarios for other areas that have the same species, as well as for other species, in order to see how they will be affected. These results can be used for applying the best management measures for current stands as well as for establishing decisions for installing future stands at a national level.
\end{abstract}

\section{Introduction}

Due to its colossal size and large time scale, the climatic system cannot be studied through experimental methods. As a result, scientists relied on climatic models. These are representations based on theory that characterize or simulate essential characteristics and mechanisms for exploring how Earth's climate works (Edwards, 2010).

The conceptual models of the cycle of carbon have also contributed to understanding climate. Chamberlin followed Tyndall's conclusions, offering a detailed explanation of global climatic changes on geologic time scales, with carbon dioxide as a main driver (Chamberlin, 1897; Chamberlin, 1898). After 1945, the meteorological prediction was one of the main applications in digital computers. In 1964, Kasahara and Washington started to study the advantages and disadvantages of the current GCM model and between 1963 and 1980, they had proposed three major GCMs already (Harper, 2008; Leith, 1965; Kasahara et al., 1967; Washington et al., 1979). Starting with the 1980s, climate modelling has oriented toward more inclusive models (Meadows et al., 1972). The first models were limited and they generated errors. Because of this, the regional 
climatic simulation involved multiple experiments (Dickinson et al., 1989). By using the modelling framework, scientists were able to assemble new combinations of models by reusing model's codes. In addition, they could realize other modelling tasks without the need for a complex and time consuming personalized codification (Edwards, 2010).

Climatic models are evaluated in numerous ways. The most common technique was to compare the model's production with the climatologic averages from observations. Another model is to set parameters (such as greenhouse gas concentrations and the position of continents) that correspond to a known paleoclimate in order to see how exactly the model will reproduce a climate that is much different from the current one. Furthermore, the climate of the XX century was reproduced by setting parameters so that they represent the passing growth of greenhouse gas effects and major volcanic eruptions.

For the present study, we have used a climatic model known as "HYPE". The model was developed by the Swedish Meteorological and Hydrologic Institute between 2005 and 2007. Even though the model was developed on Swedish characteristics, it was used successfully in agricultural areas from China that use crop rotation and can be used at a global scale (Yin et al., 2016). HYPE is hosted and continuously developed by the Hydrologic Research Unit from the Swedish Meteorological and Hydrologic Institute. The HYPE model is the main instrument of the Hydrologic Research Unit that offers new information, prognosis and knowledge about water resources from Sweden and the entire world. This is realized at a spatial and temporal scale, while addressing a large array of users. The purpose of this model was to offer information for evaluations regarding the environment and climate changes at a high resolution and for conditions in which no monitoring is realized.

In silviculture, climatic changes are more and more noticeable (Dinca et al., 2020). Together with other species such as the sea buckthorn (Costandache et al., 2016; Dinca et al., 2018) or Norway spruce (Dinca et al., 2019; Vlad et al., 2019b), the pine is one of the most influenced species by climatic changes (Costandache and Dinca 2019; Silvestru-Grigore et al., 2018; Vlad et al., 2019a).

The aim of this research was to analyze 3 pine forest ecosystems representative for Transylvania's plateau in the context of future changes concerning climate (Figure 1).

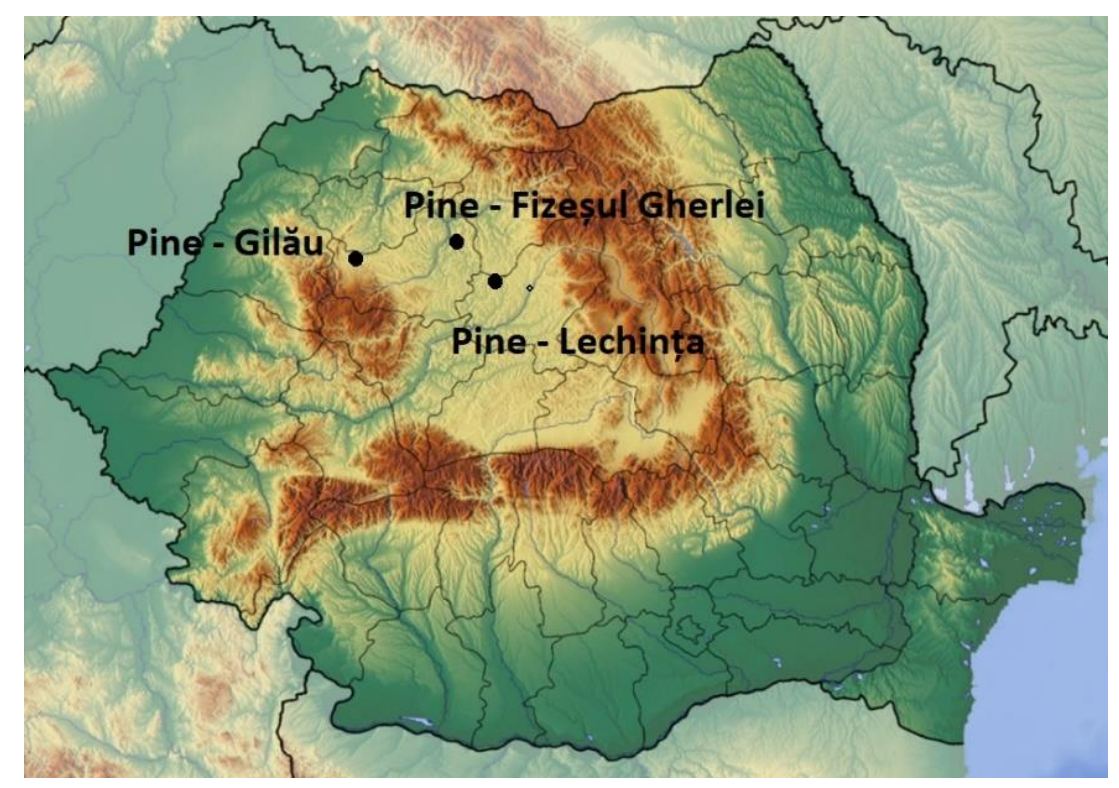

Figure 1. Location of pine plots 


\section{Materials and Methods}

We have used the "HYPE" model and its software menus for introducing entrance parameters, namely the coordinates of interest points expressed by latitude and longitude, the indicator type (in our case temperature and precipitations) as well as the wanted climatic scenario based on which the program will calculate the values of the interest parameters.

Regarding global mean temperature simulations, representative concentration pathway (RCP) project a global warming between 1 and $3.7^{\circ} \mathrm{C}$. In this way, the database to which the simulations refer (present day 1986-2005) will be exceeded with values between 1.0 (RCP 2.6) and $2.0^{\circ} \mathrm{C}$ (RCP 8.5) by the mid-21st century and between 1.0 (RCP 2.6) and $3.7^{\circ} \mathrm{C}$ (RCP 8.5) by the end of the 21st century (Quante and Colijn, 2016). According to Brutel-Vuilmet et al. (2013) the simulations of mean precipitation are characterised by several snow-related changes in the mid-latitudes of the northern hemisphere at the end of the 21st century (Brutel-Vuilmet et al., 2013). Between $40^{\circ}$ and $60^{\circ} \mathrm{N}$ the RCP scenarios project a decrease in solid precipitation of about $10 \%$ (RCP $2.6)$ to $30 \%$ (RCP 8.5), despite a marked rise in total precipitation at these latitudes. Consistent with this, snow depth declines by about $10 \%$ (RCP2.6) to $40 \%$ (RCP8.5). Räisänen and Eklund (2012) presented consistent results for northern Europe. They identified future decreases in snowfall and snow depth across all low-altitude parts of northern Europe (Räisänen and Eklund, 2012).

In the case of Hype software, we could opt between a scenario in which the greenhouse gases have a low growth ("Low - RCP 2.6"), a moderate growth ("Moderate - RCP 4.5”) or a high growth („High - RCP 8.5”) (Figure 2).

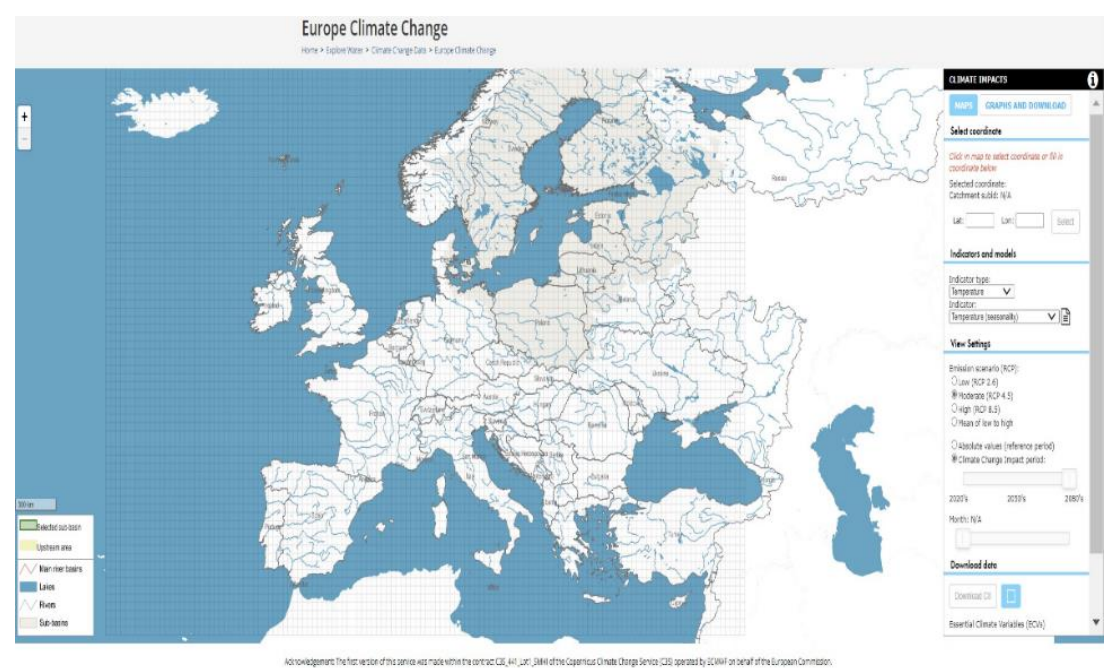

Figure 2. "HYPE” program menu

In addition, we had to select the timeframe in which the simulation could be obtained, by selecting the maximum period (in our case 2100) and then downloading the file from the "Download data" submenu.

The downloaded data are under a table form in a Microsoft Excel file and represent monthly values. It is important to mention that the historical meteorological data used for the simulation start from 1971. The data entered in this software is represented by data from the three pine plots in the Transyilvania plateau.

The HYPE Software takes into account a number of regional climatic models. REMO 2009 is a regional atmospheric model (REgional MOdel). REMO model was originally developed by the Max Planck Institute for Meteorology (MPI-M) in Hamburg. Various versions of the REMO model have already been tested all over the world for different 
geographical domains. Szépszó and Horányi evaluated the performance of the REMO model for the Hungary (Szépszó and Horányi, 2008).

For this study, we have chosen to work with the "REMO 2009" which is the most recent hydrostatic version (Jacob and Podzun, 1997; Jacob 2001). As such, the regional climatic scenario and model will be represented by "CSC_REMO2009_MPI-ESMLR_rcp45" in the case of an average increase of greenhouse gases and by "CSC_REMO2009_MPI-ESM-LR_rcp85" for the simulation with a high increase in greenhouse gases. Next, Microsoft Excel will be used for processing data, resulting in average monthly values for the studied period (1971-2100).

In order to better represent the impact of climatic changes on the studied forest ecosystems, a visual representation of Romania's map was realized illustrating how the projections will affect these ecosystems during 2020-2100. As such, a symbol was chosen for each studied climatic factor, namely the circle for average annual temperatures and the triangle for average annual precipitations, complemented by suggestive colors.

\section{Results}

This section may be divided by subheadings.

By processing the data obtained with the HYPE modelling program in Microsoft Excel, we have obtained data regarding mean anual precipitations and mean anual temperatures for each surface up to 2100 . These are rendered in a graphical form for the two scenarios: an average growth of greenhouse gasses ( $\mathrm{rcp}-4.5)$ and a high growth of greenhouse gases (rcp-8.5). As a consequence, two set of values exist for precipitations and two sets for temperatures in the case of each installed surface.

We considered the variation of the biological potential of the species depending on the studied ecological factors (temperature and precipitation) (Table 1). In order to see the effects of these scenarios on the studied forest ecosystems, we will refer to the studied species, namely the Scots pine.

As such, the Scots pine - Pinus sylvestris L. is a species that is not selective towards climate and soil and can be considered a pioneer species. The pine presents a large ecologic amplitude as it resists well at frost, while at low altitudes it supports high temperatures, insolation and heat (Sofletea and Curtu, 2008).

Table 1. Ecologic card Pinus sylvestris L. (Stanescu et al., 1997)

\begin{tabular}{|c|c|c|c|c|c|c|c|c|c|c|c|c|c|c|}
\hline \multirow{4}{*}{$\begin{array}{c}\text { Ecologic factors } \\
\text { Average annual } \\
\text { temperature } \\
\left({ }^{\circ} \mathrm{C}\right)\end{array}$} & \multicolumn{14}{|c|}{ Values or states of ecologic factors } \\
\hline & \multicolumn{14}{|c|}{ Variation of the species' biologic potential based on ecologic factors } \\
\hline & -2 & -1 & 0 & 1 & 2 & 3 & 4 & 5 & 6 & 7 & 8 & 9 & 10 & 11 \\
\hline & & & & & & I & I & o & 0 & o & o & o & 0 & sl \\
\hline Average annual & 400 & 500 & 600 & 700 & 800 & 900 & 1000 & 1100 & 1200 & 1300 & 1400 & 1500 & & \\
\hline$(\mathrm{mm})$ & & $\mathrm{s}$ & 0 & 0 & 0 & 0 & 0 & $\mathrm{~s}$ & $\mathrm{~s}$ & 1 & 1 & & & \\
\hline
\end{tabular}

We took into account the number of years that affect the ecosystems studied in terms of exceeding the limit values. The years in which the average annual temperatures exceed the limit value of the species' existence were counted. There were also counted the years when the average annual precipitations were not enough for the species to survive. In order to see how the forests are affected, we considered that thresholds represent half and a quarter out of the total number of years analyzed (2020-2100). In 
this way, forests will be severely, medium or minimally affected by future changes if the period of time will be more then 40 years, between 20 and 40 years or less than 20 years.

If we analyze the Lechinta pine stand from the perspective of annual average temperatures and annual average precipitations, we can observe that values under the established limits were present over time with years characterized by a lack of precipitations (1974, 1978, 1982 and 1985) and years with exceeding temperatures (1974, 1998, 2000 and 2006).

By applying the climatic scenarios from the HYPE modelling program, we can see a future with more years that record an annual deficiency of precipitations. The situation is also not good in the case of average temperatures - starting with 2030 , the averages increase over the species' limit for both climatic scenarios (rcp-4.5 and rcp-8.5) (Figure 3).

Amongst all the pine surfaces installed in Transylvania, Lechinta pine stand will be the one that is the hardest to be tested in the future by the two climatic factors.

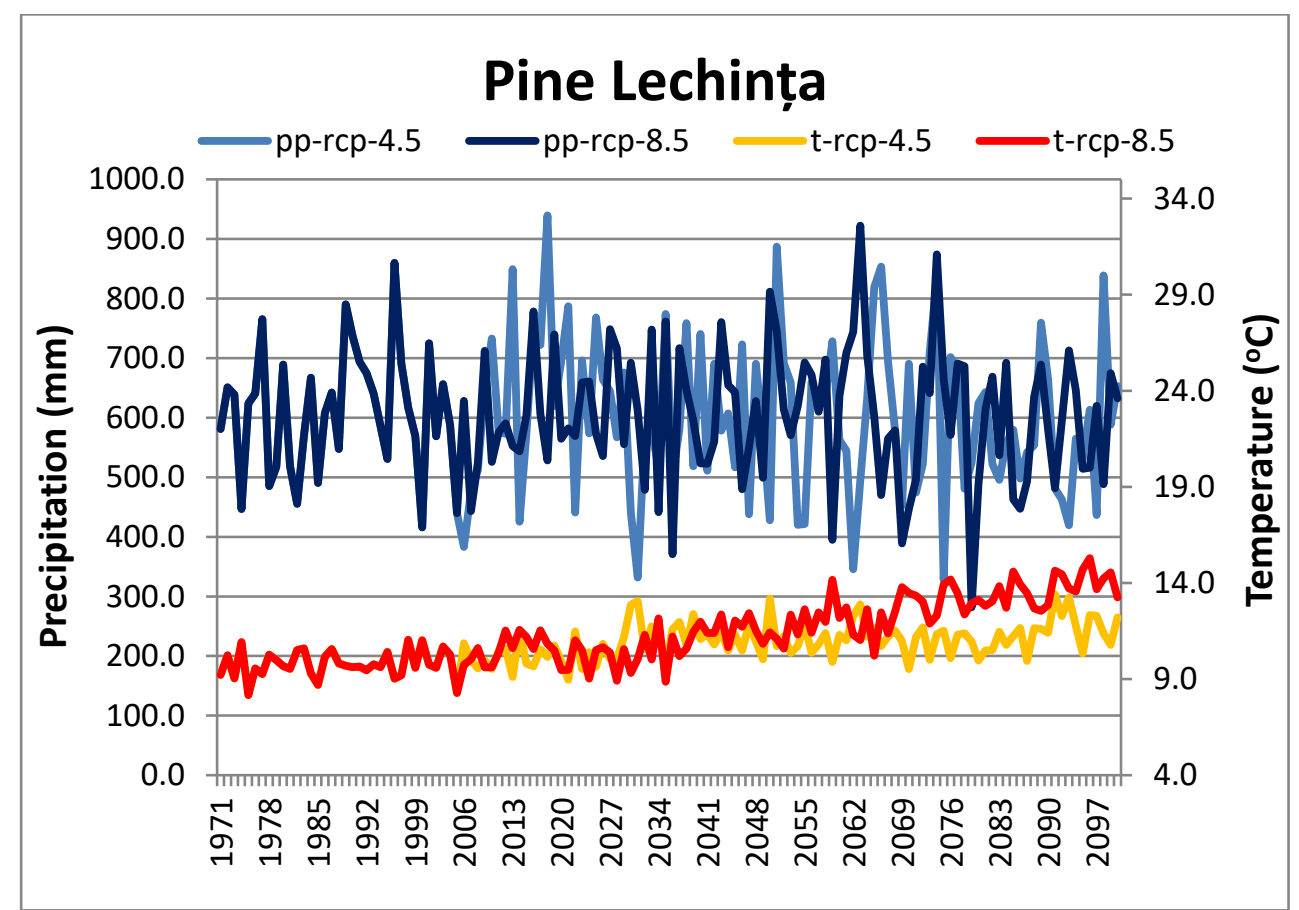

Figure 3. Climatic scenarios for the pine surface from Lechința

The pine stand situated at Fizeșul Gherlei also presents years with historical data in which the two factors record low values.

The difference between this stand and the one from Lechința consists in major problems for the temperature factor by applying the two climatic models (Figure 4). This situation will occur only in the second climatic scenario ( $r c p-8.5)$ starting with the middle of 2060.

By applying the two climatic scenarios for annual average precipitations, a rather low number of years (15 and 11 ) result in which the stand records a deficit. The stand can overlook these years as they are not grouped and have years between them when the annual average precipitations are optimum for this species (tab. 1). On the other hand, the temperature factor from the second scenario records annual exceedings of the $11^{\circ} \mathrm{C}$ limit, starting with 2066 . 


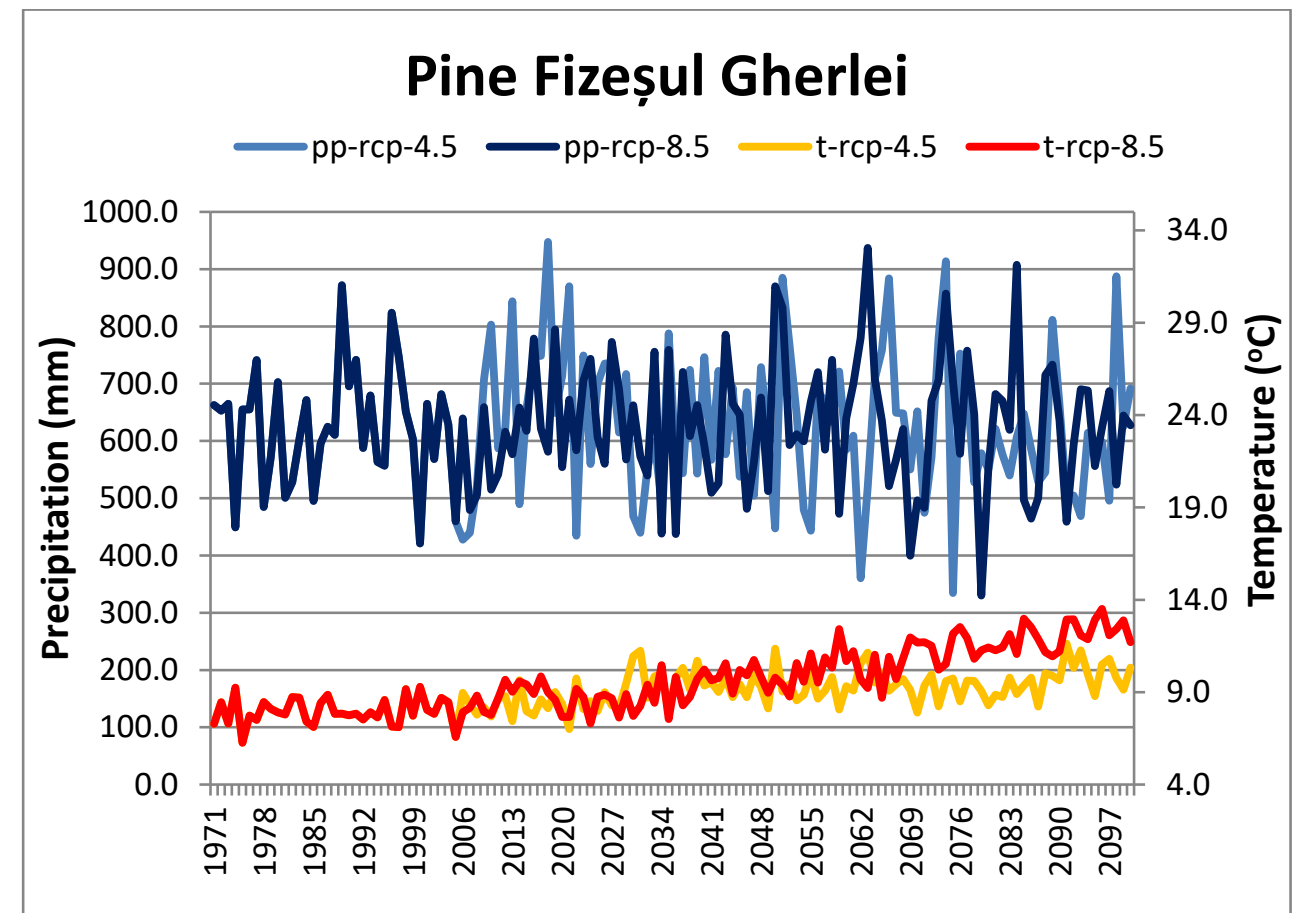

Figure 4. Climatic scenarios for the pine surface located at Fizeșul Gherlei

Similar conditions for annual average temperatures and annual average precipitations can also be found in Gilău pine stand by applying the two climatic scenarios (rcp-4.5 and rcp-8.5).

From a precipitation perspective, problems do not seem to arise in the following 80 years (Figure 5).

In the case in which the greenhouse gas concentration will increase moderately (as in the rcp-4.5 climatic scenario), the annual average temperatures will not pose big problems for the Gilău pine stand.

Only in the situation in which the greenhouse gas concentration will increase considerably (namely rcp-8.5 scenario), the annual average temperature limit will be exceeded with 2053, while substantially high values will appear from 2075.

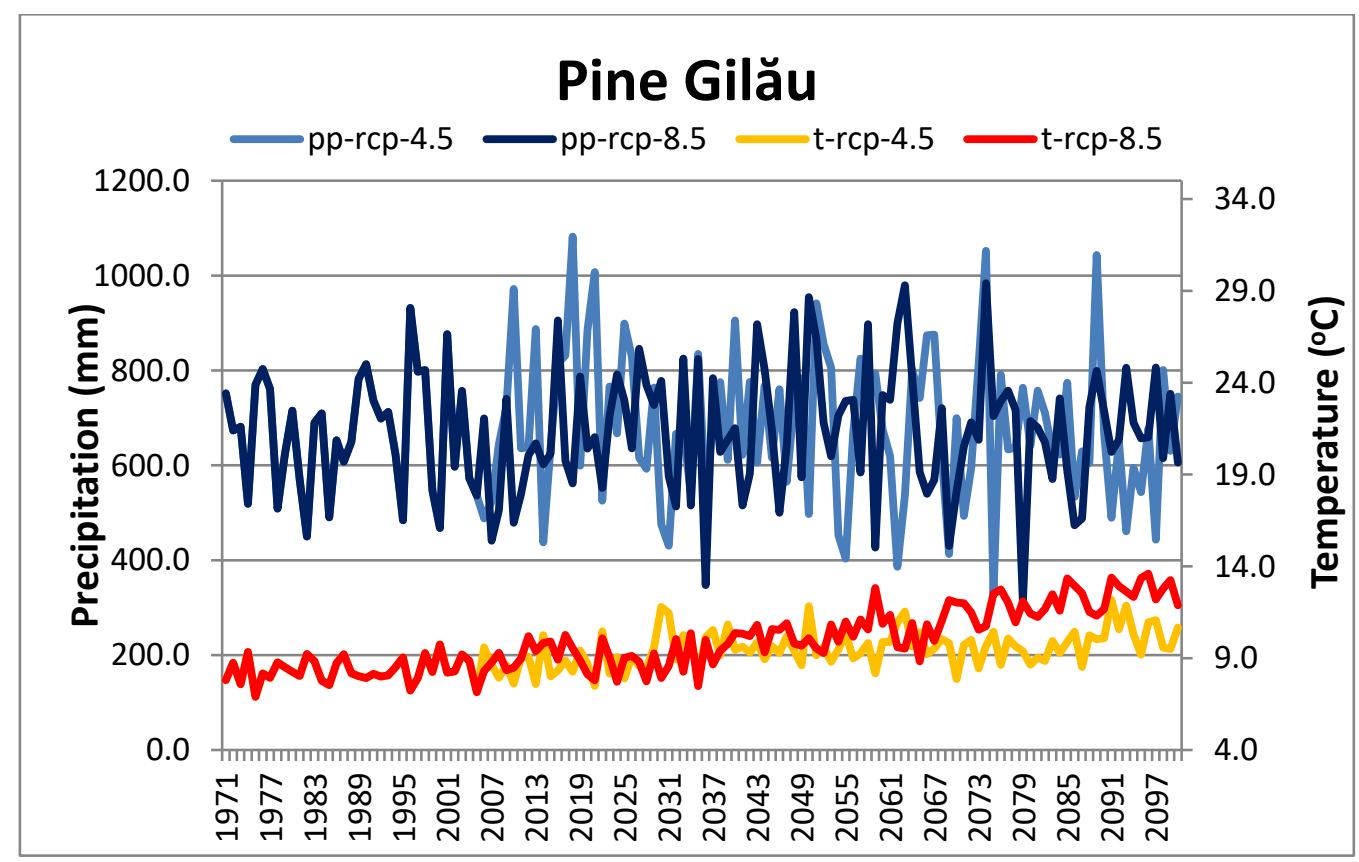

Figure 5. Climatic scenarios for the pine surface from Gilău 
The pine is the least pretentious species towards climate and soil. As such, it is considered a pioneer species as it presents a large ecological amplitude while at low altitudes it can support high temperatures, insolation and heat.

\section{Discussion}

By applying the HYPE modelling scenarios, we can see that the future presents years with an annual deficit of precipitations, but the impact will be weak. On the other hand, the impact caused by annual average temperatures will be strong. Starting with 2030, the averages increase over the limit supported by the species for both climatic scenarios (rcp-4.5 and rcp-8.5) (Figure 6 and Figure 7).

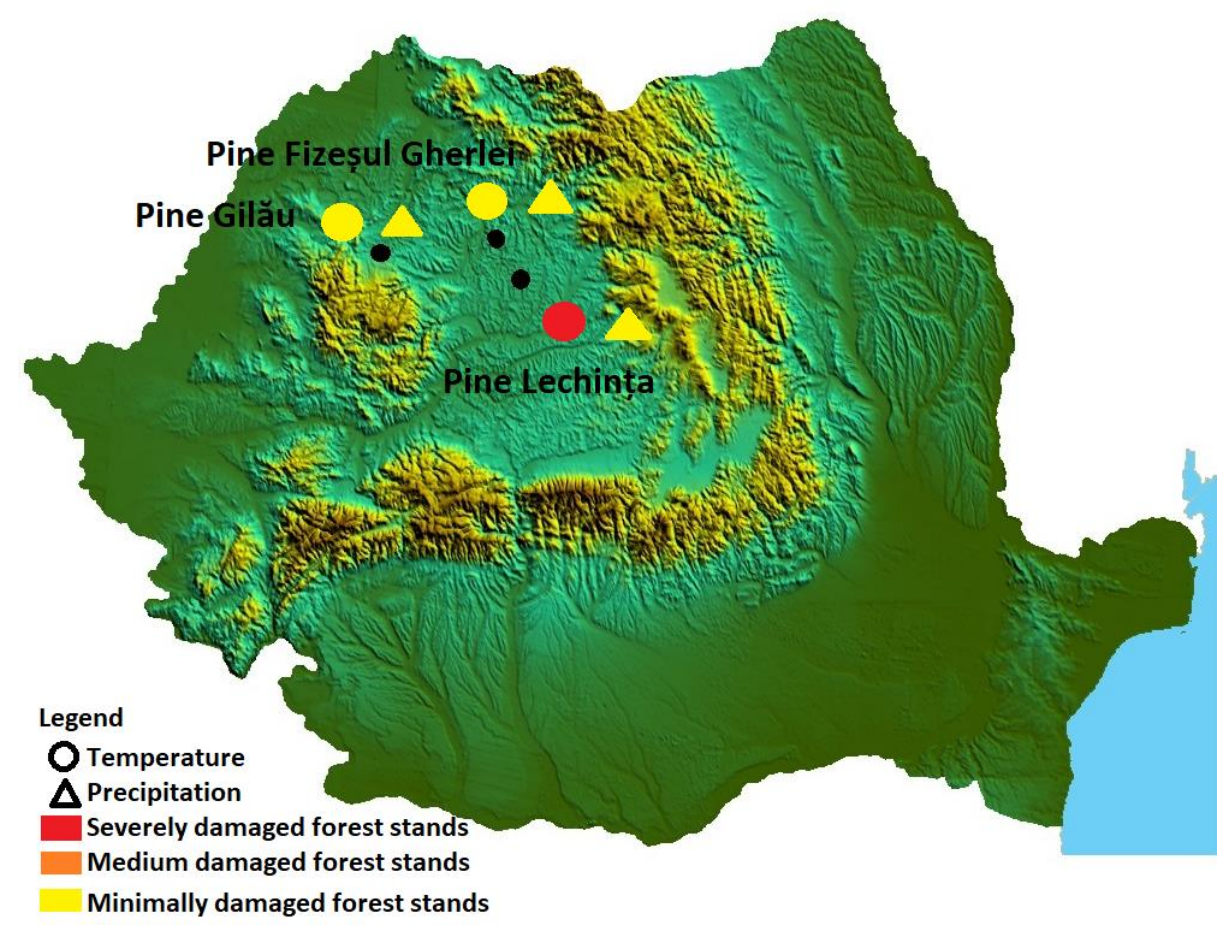

Figure 6. The impact of climatic changes on pine stands in the rcp-4.5 climatic scenario

For the pine stand from Fizeșul Gherlei serious problems will appear only for the temperature factor and only in the second climatic scenario (rcp-8.5) starting from the middle of the 2060s.

The impact of annual average precipitations is weak for both scenarios as the number of years in which the stand will record a deficit is rather low (15, respectively 11 years). The stand will be able to surpass these years as they are not grouped among themselves and have years in which the annual precipitations are optimum for this species. On the other hand, the temperature factor from the second scenario will record annual exceedings of the limit of $11^{\circ} \mathrm{C}$ starting with 2066, which leads to a strong impact on the stand.

Problems do not seem to appear in the following 80 years for the Gilau surface from the perspective of annual average precipitations applied for both climatic scenarios (Figure 6 and Figure 7).

Annual average temperatures will not increase very much even in the situation in which the greenhouse gas concentration will increase moderately (rcp-4.5 climatic scenario). As such, the impact will be weak on this pine stand. 
Only in the situation in which the greenhouse gas concentration will increase significantly (by applying the rcp-8.5 scenario) we can talk about problems. In this context, the annual average temperature limit will be exceeded from 2053 up to 2075 when substantially high values will lead to a medium impact.

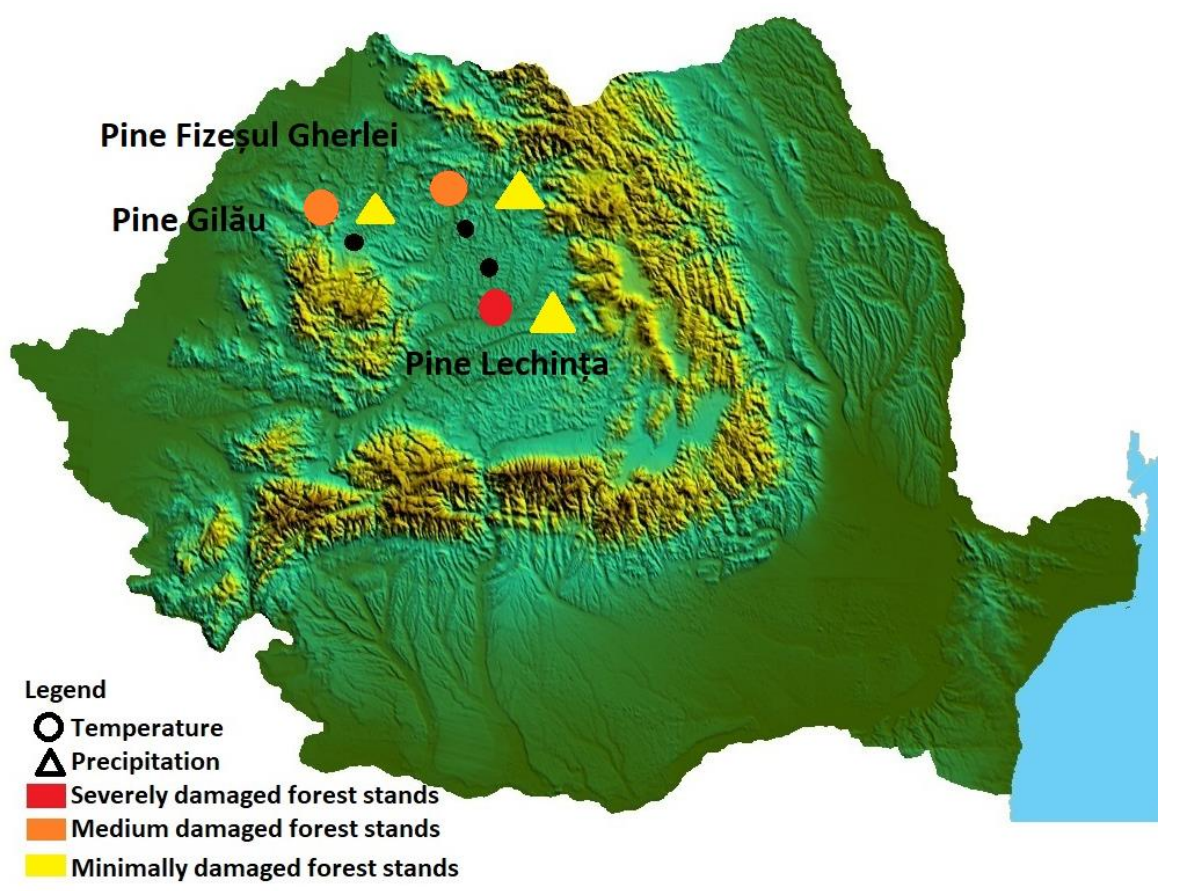

Figure 7. The impact of climatic changes on pine stands in the rcp-8.5 climatic scenario

\section{Conclusions}

The present paper has used climatic scenarios in the context of moderate and significant changes of greenhouse gas concentrations in order to analyze the effects on the Scots pine forest ecosystems from Transylvania's plateau.

The combination of high temperature values intercalated with time periods with low precipitation values will be present in future decades in both climatic scenarios and will test the resistance of pine forest ecosystems or of those in which pine predominates. This context will also have an impact on stand productivity.

Amongst all pine stands installed in Transylvania, Lechința will be the most tested in the future by these two climatic factors.

For the rcp-4.5 climatic scenario, pine stands will be weakly affected by annual average precipitations. In the same scenario, the impact of temperatures will also be weak, with a single exception - Lechinta.

It is mandatory to verify and use future climatic scenarios for other areas from our country where the same species is present as well as for other species in order to see how they will be affected in the future. Based on these results, we can take the best management measures for stands as well as establishing decisions for installing future stands.

Funding: This work was implemented by the National Institute of Research and Development in Forestry "Marin Dracea", project number 19070506 "Modelling the action of some extreme climatic factors upon forest ecosistems" within the BIOSERV programme financed by the Romanian Ministry of Research and Innovation. 


\section{References}

1. Brutel-Vuilmet C, Ménégoz M, Krinner G (2013) An analysis of present and future seasonal Northern Hemisphere land snow cover simulated by CMIP5 coupled climate models. Cryosphere, 7, pp. 67-80.

2. Chamberlin, T.C. (1897) A Group of hypotheses bearing on climatic changes. J Geol, Volume 5, 653-683.

3. Chamberlin, T.C. (1898) The influence of great epochs of limestone formation upon the constitution of the atmosphere. J Geol, Volume 6; 609-621.

4. Constandache, C.; Peticila, A.; Dinca, L.; Vasile, D. (2016) The usage of Sea Buckthorn (Hippophae rhamnoides L.) for improving Romania's degraded lands, AgroLife Sci Jou, Volume 5(2), pp. 50-58.

5. Constandache, C.; Dincă, L. (2019) The management of pine stands situated outside their habitat. Scientific Papers: Management, Economic Engineering in Agriculture \& Rural Development, Volume 19(4), pp. 59-65.

6. Dickinson, R.E.; Errico, R.M.; Giorgi, F.; Bates, G.T. (1989) A regional climate model for the western United States. Climatic change, Volume 15(3), pp. 383-422.

7. Dincă, L.; Holonec, L.; Socaciu, C.; Dinulică, F.; Constandache, C.; Blaga, T.; Peticilă, A. "Hipphophae Salicifolia D. Don - a miraculous species less known in Europe". Notulae Botanicae Horti Agrobotanici Cluj-Napoca, 2018, Volume 46(2), pp. 474-483, https://doi.org/10.15835/nbha46211155

8. Dincă, L.; Murariu, G.; Enescu, C.M.; Achim, F.; Georgescu, L.; Murariu, A.; Timiș-Gânsac V., Holonec, L. (2020) Productivity differences between southern and northern slopes of Southern Carpathians (Romania) for Norway spruce, silver fir, birch and black alder. Notulae Botanicae Horti Agrobotanici Cluj-Napoca, Volume 48(2), pp. 1070-1084. https://doi.org/10.15835/nbha48211824

9. Dincă, L.; Murariu, G.; Iticescu, C.; Budeanu, M.; Murariu, A. (2019) Norway spruce (Picea abies (L.) Karst.) smart forests from the Southern Carpathians. Int Jou of Cons Sci, Volume 10(4), pp. 781-790

10. Edwards, P.N. A vast machine: Computer models, climate data, and the politics of global warming. Publisher: MIT Press, 2010.

11. Harper, K.C. Weather by the Numbers: The Genesis of Modern Meteorology. Cambridge, Mit Press., 2008.

12. Jacob, D. (2001) A note to the simulation of the annual and inter-annual variability of the water budget over the Baltic Sea drainage basin. Meteorol. Atmos. Phys. 77, 61-73.

13. Jacob, D.; Podzun, R. (1997) Sensitivity studies with the regional climate model REMO. Meteorol. Atmos. Phys., 63, 119-129.

14. Kasahara, A.; Washington W.M. NCAR global general circulation model of the atmosphere. Mon Weather Rev, 1967, Volume 95; pp. 389-402.

15. Leith, C.E. Methods in Computational Physics. New York. Academic Press; 1965, pp. 1-28.

16. Meadows, D.H.; Meadows, D.L.; Randers, J.; Behrens, W.W. The Limits to Growth: a Report for the Club of Rome's Project on the Predicament of Mankind. New York, Universe Books, 1972.

17. Quante, M.; Colijn, F. (2016) North Sea Region Climate Change Assessment; Publisher: Springer, Cham; pp. 153-160. https://doi.org/10.1007/978-3-319-39745-0

18. Räisänen, J.; Eklund, J. (2012) 21st century changes in snow climate in Northern Europe: a high-resolution view from ENSEMBLES regional climate models. Clim Dyn, 38, pp. 25752591.

19. Silvestru-Grigore, C.V.; Dinulică, F.; Spârchez, G.; Hălălișan, A.F.; Dincă, L.C.; Enescu, R.E.; Crișan, V.E. (2018) Radial Growth Behavior of Pines on Romanian Degraded Lands. Volume Forests 9(4), 213. https://doi.org/10.3390/f9040213

20. Sofletea N.; Curtu L. Dendrologie, Editura Pentru Viață, Brașov, Romania, 2008, pp. 418.

21. Stanescu, V.; Sofletea, N.; Popescu, O. Flora forestieră lemnoasă a României. Editura Ceres, . Bucuresti, 1997, pp. 451.

22. Szépszó, G., Horányi, A. (2008) Transient simulation of the REMO regional climate model and its evaluation over Hungary. IDÖJÁRÁS Quarterly Journal of the Hungarian Meteorological Service, Volume 112(3-4), pp. 203-231. 
23. Vlad, R.; Constandache, C.; Dincă, L.; Tudose, N.C.; Sidor, C.G.; Popovici, L.; Ispravnic, A. (2019) Influence of climatic, site and stand characteristics on some structural parameters of scots pine (Pinus sylvestris) forests situated on degraded lands from east Romania. Range Management and Agroforestry, Volume 40(1), pp. 40-48.

24. Vlad, R.; Dinca, L.; Sidor, C.G.; Constandache, C.; Grigoroaea, D.; Ispravnic, A.; Pei, G. (2019) Dead wood diversity in a Norway spruce forest from the Călimani National Park (Eastern Carpathians). Baltic Forestry, Volume 25(2), pp. 238-248.

25. Washington, W.M.; Dickinson, R.; Ramanathan, V.; Mayer, T.; Williamson, D.; Williamson, G.; Wolski, R. Preliminary atmospheric simulation with the thirdgeneration NCAR general circulation model: January and July. In: Lawrence W, ed. Report of the Joc Conference on Climate Models: Performance, Intercomparison, and Sensitivity Studies. Washington: WMO/ICSU Joint Organizing Committee \& Global Atmospheric Research Programme; 1979, pp. 95-138.

26. Yin, Y.; Jiang, S.; Pers, C.; Yang, X.; Liu, Q.; Yuan, J.; Yao, M.; He, Y.; Luo, X.; Zheng, Z. (2016) Assessment of the Spatial and Temporal Variations of Water Quality for Agricultural Lands with Crop Rotation in China by Using a HYPE Model. Int. J. Environ. Res. Public Health, 13, 336. https://doi.org/10.3390/ijerph13030336

(C) 2021 by the authors. Licensee UAIC, Iasi, Romania. This article is an open access article distributed under the terms and conditions of the Creative Commons Attribution (CC BY-NC-ND) license (https://creativecommons.org/licenses/by-nc$\mathrm{nd} / 4.0)$. 